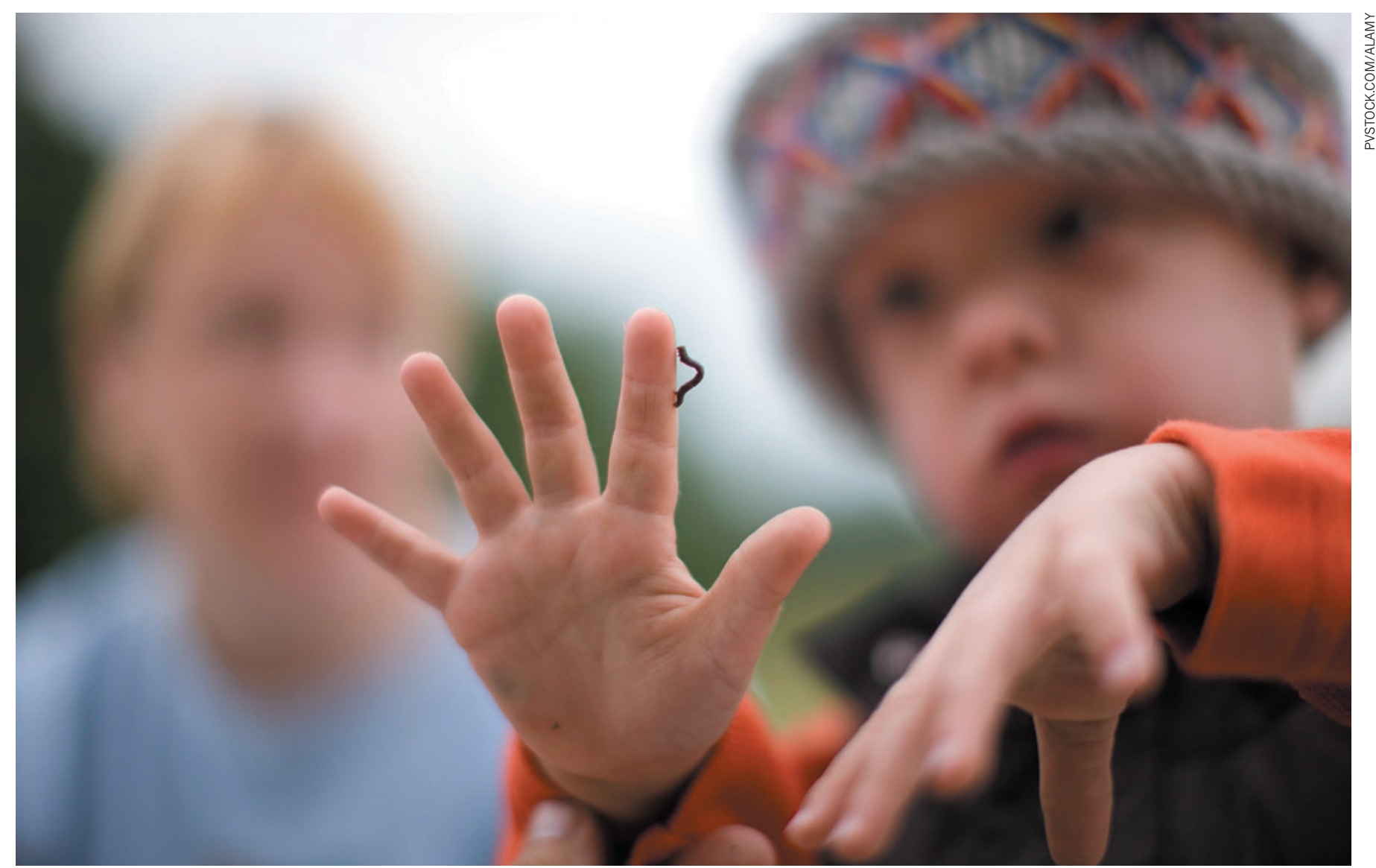

Immersive, dynamic and multidimensional, nature can stimulate and engage the whole child.

EARLY CHILD DEVELOPMENT

\title{
Body of knowledge
}

As government education experts call for toddler literacy, and baby apps proliferate, are we losing sight of materials-based learning? Infant scientists and young explorers thrive in the open air and through free play, eager to grasp the world - literally.

$\mathrm{C}$ arbon-copy playgrounds. Cramped classrooms. 'Car park' school grounds. Across the industrialized world, these are the environments in which most young children are expected to play and learn; zoo enclosures can look more enriched. Studies are emerging that reveal poor design as a hindrance to learning in the very young, as damaging as militaristic drills. Meanwhile, frogspawn and starry skies - once the recruiting agents of science - are beyond many children's experience. Here, two leading practitioners in developing learning environments for the young set out what needs to happen.

The nexus of young child and physical world is a supercharged space, where burning potential meets a chunk of the new. Developmental neuroscientist Alison Gopnik has described young children's lamp-like awareness of the world, the $360^{\circ}$ intensity of their absorption. Babies' brains grow at the gallop, making 700 new neural connections a second. By the age of 3 , a child has 1,000 trillion synapses, up to 4 times the number in an adult brain; these are later pruned.

While this neural crescendo builds, the infant and toddler is exploring the world holistically, with hands, feet and body, as well as eyes, ears, nose and mouth. Sensorimotor, materials-based learning was the bedrock of our evolution, and it shapes the brain: in his 1973 The Ascent of Man (Little, Brown), mathematician and biologist Jacob Bronowski wrote: "The hand is the cutting

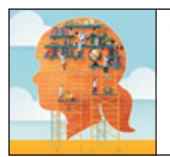

edge of the mind." It is people and things, Gopnik tells us - sand, water, a bean plant, sociable family members - that satisfy the infant scientist's experimental urge.

That young children learn how the physical world and people work so tangibly - literally getting to grips with them - militates against the idea that intensive academic settings are needed to set under-sixes on course to becoming tomorrow's synthetic biologists and solar engineers. That, cognitive scientist Guy Claxton argues, reduces learning to listening and reading, talking and writing.

E-media are often viewed as a corrective to such reductionism. But with many babies and toddlers now habitués of the virtual world - and even some nursery classrooms boasting giant digital whiteboards - electronic gadgetry is hotly debated in the earlylearning context. Whatever the final verdict, 
崖 it is clear that virtual experience alone fails to engage the whole child: screen-time limits children to what Claxton calls "eyebrain-finger" learning. It can also intrude on 'face time' and the socialization and language learning that are central to early child development. (Reportedly, prominent technocrats such as Twitter founder Evan Williams strictly limit their own children's use of electronic devices.)

Meanwhile, 'old school' alternatives to reductionism have a long pedigree. Modern findings on the importance of physicality and social contact for the very young echo the practice of pedagogical innovators and reformers from the early twentieth century on. One of Italy's first female physicians, Maria Montessori (1870-1952) - observing that cognition is closely tied to movement, and learning to autonomy - emphasized play- and materials-based education. Montessori classrooms have been compared to university labs, where children direct their own work at their own pace, with 'colleagues' of their choosing and materials designed for multifaceted experimentation. Threeyear-olds, for example, might handle and sort knobbed wooden cylinders of differing dimensions, and in the process learn the 'pincer grip' needed for manipulating fine instruments, as well as skills including reasoning and comparison, and the rudiments of maths.

A similar philosophy permeates other systems shown to boost early language use, and to strengthen reflection and self-monitoring. Finland focuses education for children up to 7 on play-based physical and social learning - and the country's 15-year-olds rank first in Europe in science and reading in surveys by the Organisation for Economic Cooperation and Development's Programme for International Student Assessment.

More radical still is forest school, rooted in the 'outdoor nursery' model of educational reformer Margaret McMillan (1860-1931), among others, and wending its way from Britain to the United States and Scandinavia between the 1910s and the 1990s. A 'classroom' might be a woodland clearing; 'lessons', fire-building or insect identification; methodology, supervised risk-taking and close observation.

Education en plein air has inspired biologists from Charles Darwin to E. O. Wilson, and the curriculum carries a range of benefits key to work at the bench. A study of UK forest schools, commissioned by the Forestry Commission and run by Forest Research and think-tank the New Economics Foundation, found improvements in children's confidence, concentration, fine motor control and teamwork. Forest schools also offer tangible evidence of abstract phenomena such as life cycles, food chains and materials behaviour (such as why wood blackens in a fire).

Nature is unsurpassed as a teaching

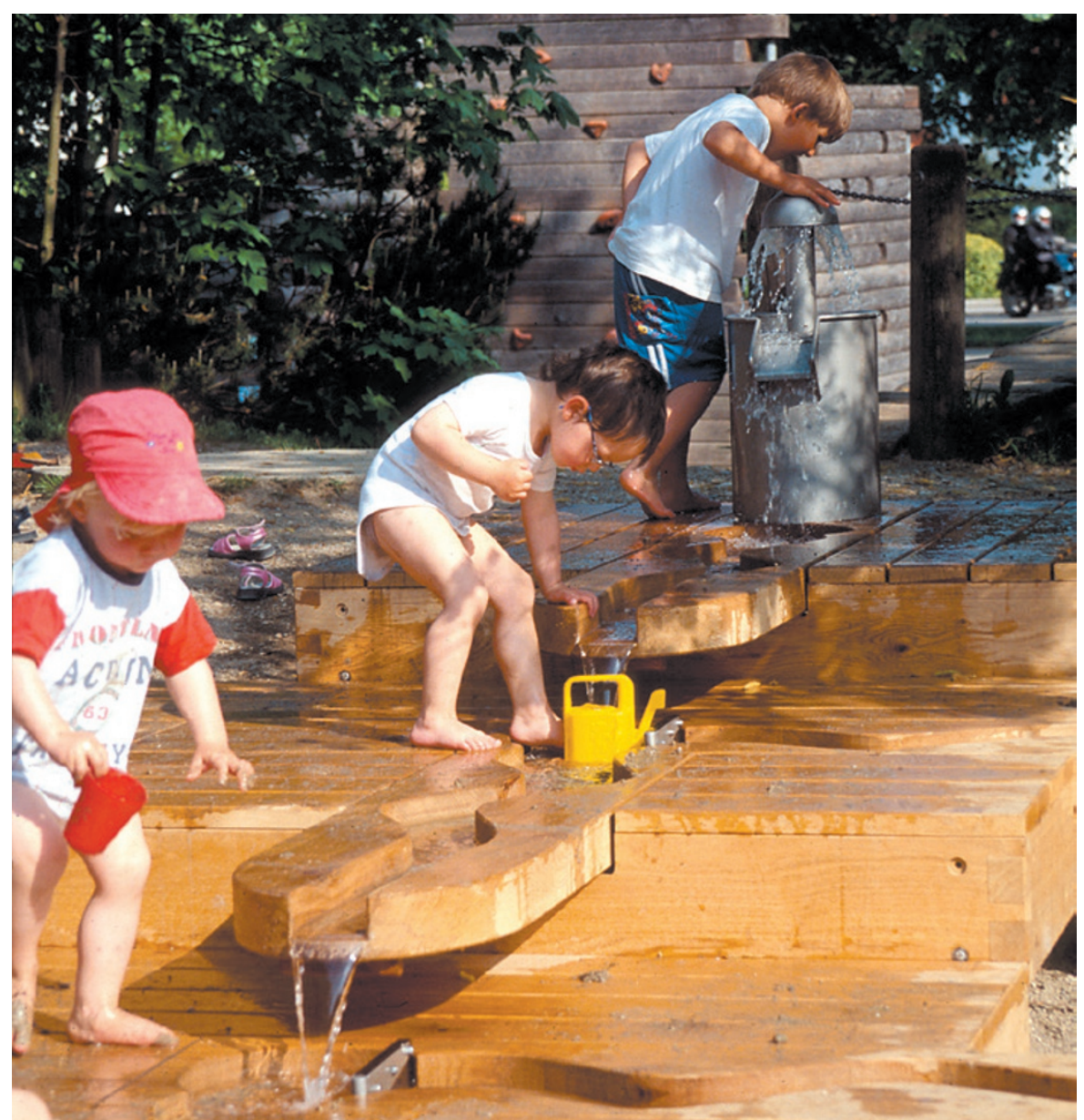

Günter Beltzig's playspaces often give opportunities for learning about materials.

environment, argues social ecologist Stephen Kellert on page 288. A meadow or seashore is an immersive experience, engaging and challenging the whole child physically, socially, cognitively and emotionally. Complex and unexpected, a drama of rain, wind, birds flying, mud squelching and leaves falling, nature sparks curiosity even as it provides an arena for free play - both gripping detail and far horizons.

But with the wild giving way to trafficridden tarmac, safe places for full-on play (and outdoor learning) become ever more important as refuges and testing grounds for children. 'Quality' play that stretches a child's senses, intellect, sociality, physicality and motor skills both gross and fine demands spaces designed to accommodate children's needs and behaviour, notes renowned playspace designer Günter Beltzig on this page.

As educational theorists, teachers, governments and parents tussle endlessly over literacy, numeracy and testing in the undereights, we sometimes forget that nature nurtures. We ascended as a species through incandescent curiosity - that hallmark of scientists in every century - at play in the world. Those primal, physical realities still have everything to teach us, in one way or another. Barbara Kiser
GÜNTER BELTZIG Learn to play, play to learn
Industrial and playground designer, Hohenwart, Germany.

An urban space equipped with a slide and swings is known as a playground. Most such spaces are designed by landscape architects. There is still no academic underpinning to playground-design theory, even though there is for graveyard design. The body of knowledge on children's behaviour gathered by educationalists, psychologists and neuroscientists has not permeated playground design, so most such spaces fail to inspire play and the physical, emotional, social and psychological development that it engenders.

Designers are trained in creating and problem solving, and in materials and production science. But to create an environment for children, you need to behave like an anthropologist, respecting the 'otherness' of children. You learn by reflective observation to discover their needs, possibilities and aims (see 'Six rules for play spaces'). 


\section{PLAY FOR KEEPS \\ Six rules for play spaces \\ - Communicate that this is a place to linger - neither a training ground nor a display area for structures attuned to an adult aesthetic. \\ - Allow the discovery of things that expose themselves only to the seeker, such as a nook cut into a hedge. - Give opportunities to experiment with self-controlled, obvious and manageable risk, for example with the ability to climb to different levels. \\ - Allow different groups to find desirable places according to mood, interests or needs. \\ - Provide shelter from wind, noise and observation by others. \\ - Avoid superfluous bans.}

> Being a child is a fluid, constantly changing process. Whatever a child is capable of doing today, they might not have achieved yesterday; whatever they will be doing tomorrow, they might not do today. This ongoing 'newness', this changing of mind, this physiological development, comes in waves - not in a constant rhythm. Some develop early, others travel on a later wave.

The continuing changing of body and mind leads to a sort of constant discourse within the capabilities that the child has. This self-experimentation to find those capabilities, harnessing unbiased, spontaneous fantasy, creativity, curiosity, is what playing really is. It is the origin of learning, not just with your brain, but in combination with intuition and feelings, with your body: learning as a whole being. It is goal-free discovery through experimentation, in a world where the child is the decision-maker, not the decided-for. For this sort of learning, a child needs time, freedom of possibilities and space. For our increasingly urbanized species, that space is the playground.

The characteristics of the community will dictate playground design to a degree. Neighbourhoods differ socio-economically and demographically as well as in topography, infrastructure and degree of urbanization. Inside the play space, the layout and nature of features will determine the children's behaviour, and so demand informed design to ensure that the children's needs and wants, individually and collectively, are met.

Components for climbing and balancing - such as ladders, ropes and hanging

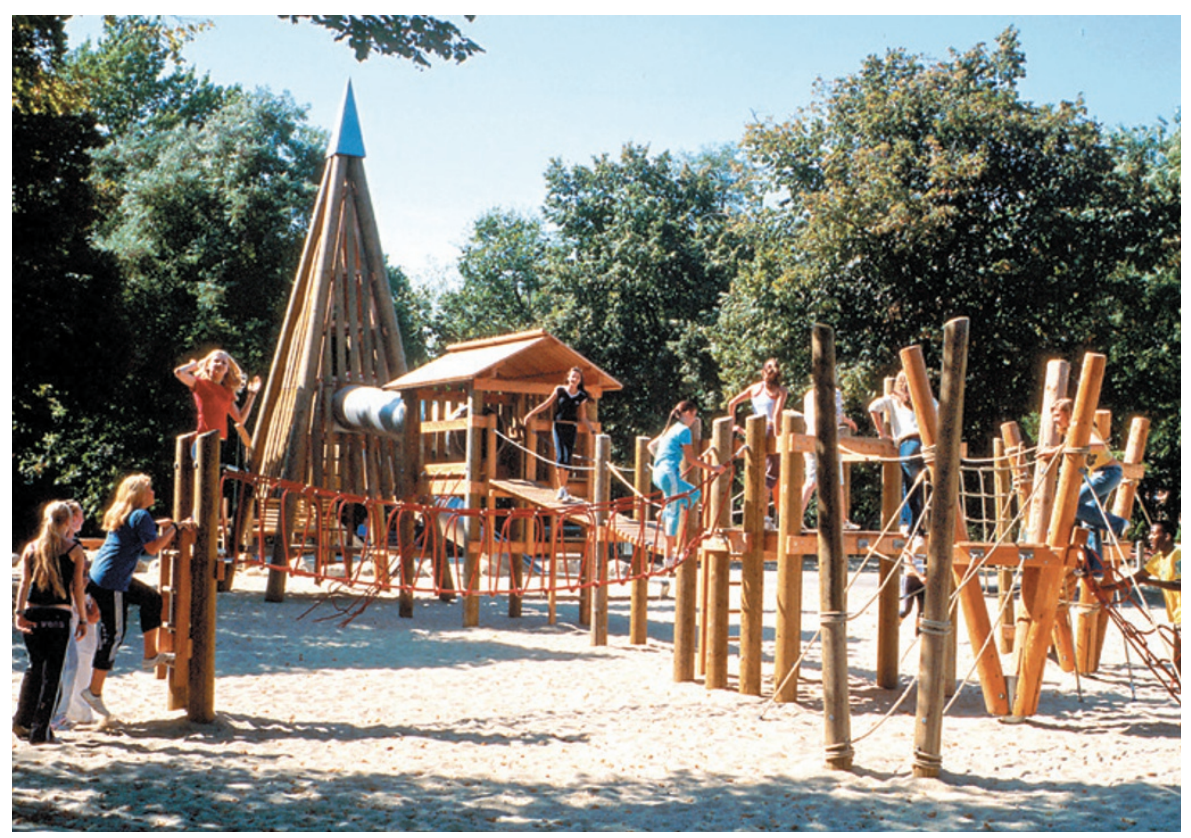

Play towers and bridges offer the chance to take manageable risks, such as climbing and balancing.

bridges - foster planning, problem solving, physical coordination, body control, risk management and the chance to work on reaction time, as well as an understanding of capabilities and shortcomings. Climbing equipment should always be part of a wider schema and have an objective, such as offering a shortcut or a way to a platform. In isolation, it will lead to disputes over territory.

Towers and high-level playhouses offer vistas: the experience of seeing the world differently and from above. This can feel transformative for the child, so high structures are hugely popular and demand multiple ways of climbing up and down simultaneously, as well as extremely sturdy construction.

Shared spaces allow the growth of selfassertiveness and social intelligence, but calm spaces for daydreaming and relaxing offer the chance to reflect, think or escape. Wicker playhouses, hollows in shrubs or low-level huts for quiet play should be located away from the most popular equipment.

Sandboxes should mimic natural hollows, built below ground level to prevent loss of sand. They encourage the exploration of materials and, in combination with equipment such as excavators and wagons for digging and transporting sand, provide opportunities for physical fitness, technical experience and teamwork.

Figures should be functional rather than merely decorative. Children do not necessarily share adult aesthetics. More importantly, they are interested in simple shapes, suggestive rather than representative, which can be adapted in imaginative play: a log can be a horse or motorcycle, a litter bin a spaceship.
Inclusive play spaces for children of all abilities need particular tailoring. Children with hearing impairment are limited to their field of vision, so moving components must be highly distinctive - differently coloured, for example. Children with visual impairment need safety areas distinguished by barriers or different surfacing. Wheelchair use demands close attention to surfacing and dimensions, and the placement of some play components, such as tube phones, along paths.

No playground is perfect. When I watch children play in one that I have designed, I see them use it in ways I had not thought of. To enable children to experiment freely and curiously through play, developmental psychologists and playground designers need to find a meeting place. Our urbanizing world is essentially hostile to children, so the creation of play spaces honouring what the young themselves want and need is, in my view, central to bettering global society.

STEPHEN KELLERT Build nature into education

\author{
Professor emeritus and senior \\ research scholar, Yale School of \\ Forestry and Environmental Studies, \\ New Haven, Connecticut.
}

The typical child in the United States now spends $90 \%$ of the time indoors. US children aged 2-5 engage in electronic media for an 


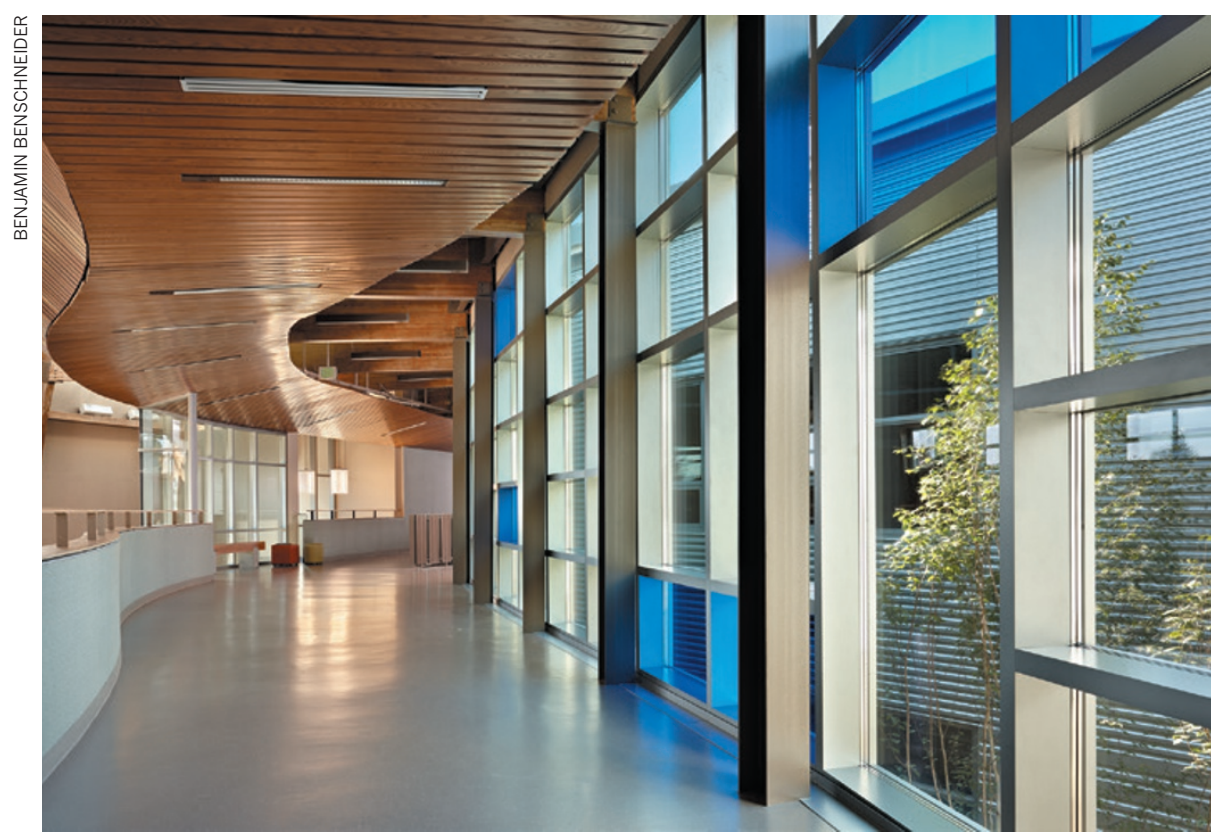

Machias Elementary School in Snohomish, Washington state, is an example of biophilic design.

average of more than 30 hours per week; for 8-18-year-olds the figure is 52 hours. Most children devote just 30 minutes daily to unstructured outdoor play; a generation ago, it was more than 4 hours. Many parents fear letting their children play outdoors on their own, and see learning as a formal indoor process.

A growing body of evidence from US, European and Australian studies - reviewed in Stephen Moss's 2012 publication Natural Childhood, produced for the UK National Trust - suggests that this disconnection may be causing physi-

cal, emotional and intellectual deficits in children's learning and development. A young child engaged in free play in a grove

\section{"The centrality} of nature in children's learning begins with our origins as a species." experience and nurturance. The reliance on learning is the source of our species' remarkable inventiveness, yet it also carries the potential for us to behave in ways contrary to our long-term biological self-interests.

Beyond a vague awareness that the 'outdoors' is good for kids, we are only starting to explore the role of nature in learning and development. The scientific evidence remains limited, but findings in health care, education, work, recreation and community indicate that contact with nature remains vital to child development, and it may not be possible to find a substitute. A study of 90 schools for children aged 5 to 12 in Australia, for example, found that being outdoors improved the children's self-confidence, ability to work with others, caring, peer relationships and interaction with adults (C. Maller and M. Townsend Int. J. Learn. 12, 359-372; 2006).

Immersion in the sensory and informational richness and dynamic qualities of woodlands, beaches and meadows evokes basic learning responses such as identification, differentiation, analysis and evaluation. Children distinguish big trees from little trees, house plants from garden plants, vines from ferns, ants from flies, ducks from songbirds, real creatures from imaginary ones. They develop quantitative skills by counting insects and flowers; gain materials knowledge from playing in grass and mud; intuit physics from how creek water responds to obstacles and opportunities. In recognizing hills, valleys, lakes, rivers and mountains, they learn geological form. In engaging with other life from redwood trees to hedgehogs, they encounter an endless source of curiosity, emotional attachment and a motivation for learning. In adapting to the ever-changing, often unpredictable natural world, they learn to cope and problem-solve.

Alan Ewert's classic 1989 book Outdoor Adventure Pursuits (Gorsuch Scarisbrick) reviewed studies of children participating in nature programmes, and found that these children asked more questions than others, and were better at solving problems. A study of 262 children aged 3-12 in poor neighbourhoods in Chicago, Illinois, demonstrated richer creative play following exposure to nature (A. Faber Taylor et al. Environ. Behav. 30, 3-27; 1998).

Unfortunately, modern society has erected increasing barriers to children's contact with nature. Children's residential, educational and recreational environments, for example, are often highly artificial and sensorily deprived. A new paradigm is needed: biophilic design. This approach to building and landscape design encourages direct and indirect contact with nature, and an experience of place evoking children's evolved affinities for the natural world.

The direct experience of nature - light, air, plants, animals, water and landscapes - can be designed, for example, through abundant use of plants indoors and outdoors; subtle manipulations of airflow, temperature and pressure; and outside views. Nature-inspired artwork, the use of materials such as wood and wool, and designs that mimic natural form can provide an indirect experience of the living world. So, too, can sheltered spaces with long views and visual connections to the outside, and areas rich in natural features, yet orderly and understandable.

Biophilic design has the potential to transform children's schools and play areas. A recent example is the new Sandy Hook Elementary School in Newtown, Connecticut, under construction on the site of the 2012 shootings where 20 children died. The original school was widely seen as a barren structure. The new school, for which I was a design consultant, contains extensive natural lighting and materials, outside views, widespread planting and courtyards, and constructed wetlands. Its biophilic design features encourage learning and, just as importantly, affirm life at this site of unimaginable loss.

The natural world is more than a decorative backdrop or a dispensable amenity. Experiencing it is an act of profound self-interest, a guard against a future as imperilling to the long-term fitness of our species as the more obvious threats of poverty and disease. 